\title{
The association between smoking cessation before and after diagnosis and non-muscle-invasive bladder cancer recurrence: a prospective cohort study
}

\author{
Frits H. M. van Osch ${ }^{1,2}\left(\right.$ - Sylvia H. J. Jochems ${ }^{1,2} \cdot$ Raoul C. Reulen $^{3}$. Sarah J. Pirrie ${ }^{2}$. Duncan Nekeman ${ }^{1,2}$. \\ Anke Wesselius $^{1} \cdot$ Nicholas D. James $^{2,4} \cdot$ D. Michael A. Wallace ${ }^{2,4} \cdot$ K. K. Cheng ${ }^{3} \cdot$ Frederik J. van Schooten $^{5}$. \\ Richard T. Bryan ${ }^{2} \cdot$ Maurice P. Zeegers ${ }^{1,6}$
}

Received: 6 April 2018 / Accepted: 28 May 2018 / Published online: 30 May 2018

(c) The Author(s) 2018

\begin{abstract}
Background Smoking is a major risk factor for bladder cancer, but the relationship between smoking cessation after initial treatment and bladder cancer recurrence has been investigated less frequently and not prospectively yet.

Methods 722 non-muscle-invasive bladder cancer (NMIBC) patients (pTa, pT1, and CIS) from the prospective Bladder Cancer Prognosis Programme (BCPP) cohort, selected in the UK between 2005 and 2011, provided complete data on smoking behavior before and up to 5 years after diagnosis. The impact of smoking behavior on NMIBC recurrence was explored by multivariable Cox regression models investigating time-to-first NMIBC recurrence.

Results Over a median follow-up period of 4.21 years, 403 pathologically confirmed NMIBC recurrences occurred in 210 patients. Only 25 current smokers at diagnosis quit smoking (14\%) during follow-up and smoking cessation after diagnosis did not decrease risk of recurrence compared to continuing smokers $(p=0.352)$.

Conclusions Although quitting smoking after diagnosis might reduce the risk of recurrence based on retrospective evidence, this is not confirmed in this prospective study because the number of NMIBC patients quitting smoking before their first recurrence was too low. Nevertheless, this indicates an important role for urologists and other health care professionals in promoting smoking cessation in NMIBC.
\end{abstract}

Keywords Smoking $\cdot$ Smoking cessation $\cdot$ Bladder cancer $\cdot$ Prognosis $\cdot$ Recurrence $\cdot$ Epidemiology

\section{Introduction}

Bladder cancer (BC) is estimated to be the ninth most frequent cancer worldwide with approximately 400,000 newly diagnosed cases per year [1]. Compared to other cancers, mortality rates are generally lower for $\mathrm{BC}[1]$ since the

Frits H. M. van Osch

f.vanosch@maastrichtuniversity.nl

1 Unit of Nutritional and Cancer Epidemiology, Chairgroup of Complex Genetics and Epidemiology, School for Nutrition and Translational Research in Metabolism (NUTRIM), Maastricht University, Maastricht, The Netherlands

2 Institute of Cancer and Genomic Sciences, University of Birmingham, Birmingham, UK

3 Department of Public Health and Epidemiology, University of Birmingham, Birmingham, UK majority of $\mathrm{BCs}$ diagnosed are non-muscle-invasive bladder cancers (NMIBC) [2]. However, NMIBC often recurs [3] and has a risk of progressing to muscle-invasive bladder cancer (MIBC) [4], events which impact on the quality of life of the patient [5] and generate high disease management costs [6].

4 University Hospital Birmingham, NHS Foundation Trust, Birmingham, UK

5 Department of Pharmacology and Toxicology, School for Nutrition and Translational Research in Metabolism (NUTRIM), Maastricht University, Maastricht, The Netherlands

6 Chairgroup of Complex Genetics and Epidemiology, Care and Public Health Research Institute (CAPRHI), Maastricht University, Maastricht, The Netherlands 
Although smoking is an established risk factor for $\mathrm{BC}$, its effects has been less frequently investigated in relation to $\mathrm{BC}$ prognosis [7-10]. Although many studies investigated effectiveness of treatment for NMIBC and MIBC with regard to recurrence, progression, and mortality, most studies did not investigate the effect of smoking or other factors modifiable by patients on BC prognosis [11]. Nevertheless, the number of studies also reporting hazard ratios (HRs) for $\mathrm{BC}$ recurrence by smoking status at diagnosis has increased recently and the current body of evidence consistently shows that there is a small association between smoking and BC recurrence when comparing current smokers to never smokers at diagnosis $[10,12]$. However, the impact of smoking cessation after BC diagnosis on recurrence and mortality has not yet been quantified prospectively [13]. Studies have investigated the impact of smoking cessation within 1 year after diagnosis on $\mathrm{BC}$ recurrence, showing a slight decrease in risk of recurrence [14, 15], and one study indicates no effect of quitting after diagnosis on overall or bladder cancer-specific mortality [16].

The Bladder Cancer Prognosis Programme (BCPP) followed up BC patients for 5 years post-diagnosis and investigated changes in smoking behavior in relation to the course of the disease [17]. The principal aim of this study was to investigate whether smoking cessation post-diagnosis and smoking behavior pre-diagnosis influences $\mathrm{BC}$ recurrence.

\section{Methods}

\section{The Bladder Cancer Prognosis programme}

This study was conducted within the framework of the West Midlands Bladder Cancer Prognosis Programme (BCPP), a cohort study in the United Kingdom. Details of the study are described elsewhere [17]. In brief, individuals were included between December 2005 and October 2011 after referral to participating urology centers due to symptoms suspicious of $\mathrm{BC}$ and followed for a maximum of 5 years from diagnosis. Patients with previous cancer of the urethra, bladder, ureter, or renal pelvis within the last decade were excluded. The study was ethically approved (06/MRE04/65) and all participants gave written informed consent.

\section{Data collection}

At or around time of diagnosis, trained research nurses used semi-structured face-to-face interviews and questionnaires to collect data on social support, health-related quality of life, sociodemographics, medical history, and health-related behaviors including smoking behavior. Variables on smoking behavior included current smoking status (never, former, current), duration (years of smoking), intensity (cigarettes per day), smoking cessation (in years), and tobacco type (filter, non-filter, or rolled cigarettes, cigar, or pipe). Monthly smoking status was also assessed retrospectively by postal questionnaires that were sent out to participants yearly until the end of follow-up.

\section{Smoking status at diagnosis and during follow-up}

A combined smoking status variable was created indicating continuing smokers, former smokers who consistently abstained, never smokers, former smokers who started smoking again, and current smokers who quit smoking post-diagnosis. Patients were considered quitters when they abstained consistently, so smokers who quit for 3 months and then started again were considered as continuing smokers. Furthermore, for each participant that reported smoking cessation during follow-up, it was confirmed whether this occurred before or after their first recurrence. If patients quit smoking after their first recurrence, they were considered as continuing smokers in the time-to-first recurrence analysis.

\section{Population at risk}

Of the 1,550 cases who agreed to participate, 231 were subsequently identified as not having BC. Patients who presented with MIBC $(n=275)$ disease at diagnosis were excluded from analysis because they are fundamentally different from NMIBC with regard to recurrence. Patients with squamous or adenocarcinomas of non-urothelial origin or with bladder cancer as secondary carcinoma were excluded $(n=41)$. In addition to patients presenting with Ta and $\mathrm{T} 1$ tumors, carcinoma in situ (CIS) tumors were included $(n=16)$ since they have an increased risk of recurrence [18]. In total, $846(84 \%)$ of these patients had provided data on smoking behavior at diagnosis and during follow-up and remained under follow-up within the cohort study. Of the included 846 NMIBC patients, there were 116 patients with unknown recurrent tumor stage. These 116 unconfirmed events were excluded for other analyses as well as 8 cases who had radiotherapy (on suspicion of being MIBC cases) resulting in a NMIBC patient population at risk of recurrence of 722 .

No systematic guidance or tools were provided to enable patients to quit smoking after diagnosis, so care as usual was applied by all participating urologists.

\section{Statistical analysis}

$\mathrm{BC}$ recurrence was defined as a new tumor that was at the same stage as the primary tumor (Ta or T1) but also when a primary Ta patient had a T1 recurrence. Patients that progressed from $\mathrm{T} 1$ to $\mathrm{T} 2$ disease were not counted as a recurrence but as a progression event. Unfortunately, there were 
not enough events to also consider biological progression within this sample of NMIBC patients, as defined in the BCPP cohort [19]. Therefore, this study only focussed on confirmed recurrence events and patients who experienced a progression event were censored in the survival analysis when the progression event was diagnosed.

The impact of smoking behavior on $\mathrm{BC}$ recurrence was explored by Cox regression models-with time since initial transurethral resection of the bladder tumor (TURBT) as the time-metric-investigating possible differences in likelihood of a first recurrence. We explored two different Cox regression models: one adjusted for age at diagnosis and sex (model 1) and one additionally adjusted for BC stage, grade, tumor size, and number of tumors at diagnosis (model 2). This set of confounders was chosen since they are markers of NMIBC prognosis and are factors that contribute to European Association of Urology (EAU) risk stratification for clinical decisions [20]. Moreover, they are potentially associated with smoking behavior at diagnosis [21]. Consequently, conditional risk set modeling was applied to investigate time between multiple recurrent events and analysis time was reset at each event [22]. For this analysis, re-resection of tumors was added to model 2 as a confounder. The proportional hazards assumption was checked in all models using Schoenfeld residuals. Cumulative incidence functions (CIF) corrected for competing risks (death) were made [23].

Furthermore, the differences in mean number of recurrences over 5 years between never smokers, former smokers, and continuing smokers were compared using a multivariable ANOVA model correcting for pairwise comparisons using Tukey's HSD. There were not enough BC-related death events (45) or confirmed progression events (19) to allow for separate analyses. A similarly low number of progression events has been observed in a large $(n=718)$ NMIBC patient sample before [24].

NMIBC patients who died before the end of follow-up $(n=157)$ were censored at time of death, and patients who underwent cystectomy $(n=15)$ were censored at the date of cystectomy (13). Other patients were considered lost to follow-up when the date on which patients were last seen in the hospital for bladder cancer-related therapy or the date on which they filled in their last follow-up questionnaire was before the end of follow-up (5 years).

\section{Results}

\section{Number of recurrences and characteristics of population at risk}

All 722 patients at risk of recurrence were followed over a median period of 4.21 years (IQR 2.64-5.00 years). The majority of patients $(506,70 \%)$ were followed for at least
3 years. Over this period of follow-up, 210 NMIBC patients experienced at least one confirmed recurrence event. These 210 NMIBC patients accumulated a total of 403 confirmed recurrence events in the cohort.

Most cases were male (79\%) and around the age of 70 (Table 1). Furthermore, continuing smokers seemed to be underrepresented in the low EAU risk group (12\%), those who quit smoking seemed more likely to be younger and female, and continuing smokers seemed more likely to present with multiple tumors at diagnosis (Table 1). In the multivariate models, 26 patients were not included in the analysis due to missing data on age $(n=7)$, number of tumors at diagnosis $(n=15)$, and tumor size $(n=4)$. Because participants were recruited from multiple centers, patients were treated by multiple urologists with different individual thresholds to perform certain therapies. Therefore, not all patients were treated exactly according to the EAU guidelines [20], which is often the case in actual clinical practice [25].

\section{Associations between smoking behavior pre- and post-diagnosis and $B C$ recurrence}

Although HR estimates for smoking cessation pre-diagnosis indicated a protective association with $\mathrm{BC}$ recurrence, the $p$ for linear trend was not statistically significant $\left(p_{\text {trend }}=0.126\right)$ and therefore the association cannot be considered as strong (Table 2). No association between smoking status and risk of recurrence was observed in the multivariable model (Table 2). Interestingly, when compared to continuing smokers (HR 1.04, 95\% CI 0.65-1.66), HRs were similar for those who quit smoking $(p=0.352)$ and former smokers who started again post-diagnosis $(p=0.431)$ (Table 2). Additionally, the cumulative incidence function shows that cumulative incidence of $\mathrm{BC}$ recurrence was lowest for former smokers and never smokers (Fig. 1).

Only 25 smokers (14\%) of the 174 current smokers originally recorded at diagnosis quit smoking at any point during follow-up. Three quitters were excluded for full analysis for not having information on their date last seen and another five had missing data regarding the invasiveness of their recurrent events. Of the 480 former smokers at diagnosis, $172(36 \%)$ started smoking (any form of tobacco) again postdiagnosis in all included 846 NMIBC patients.

Exposure to environmental tobacco smoke during childhood (HR 1.17, 95\% CI 0.81-1.68) or adulthood (HR 1.02, 95\% CI 0.76-1.36) did not seem to have any impact on timeto-first recurrence (Table 2).

Table 3 shows HRs for time-to-first recurrence by smoking intensity, duration, and pack-years. No linear trends were observed although the highest categories showed the highest point estimates for both smoking intensity and pack-years. 
Table 1 Patient characteristics at diagnosis and number of recurrences over 5 years for 722 NMIBC patients treated with transurethral resection by smoking category

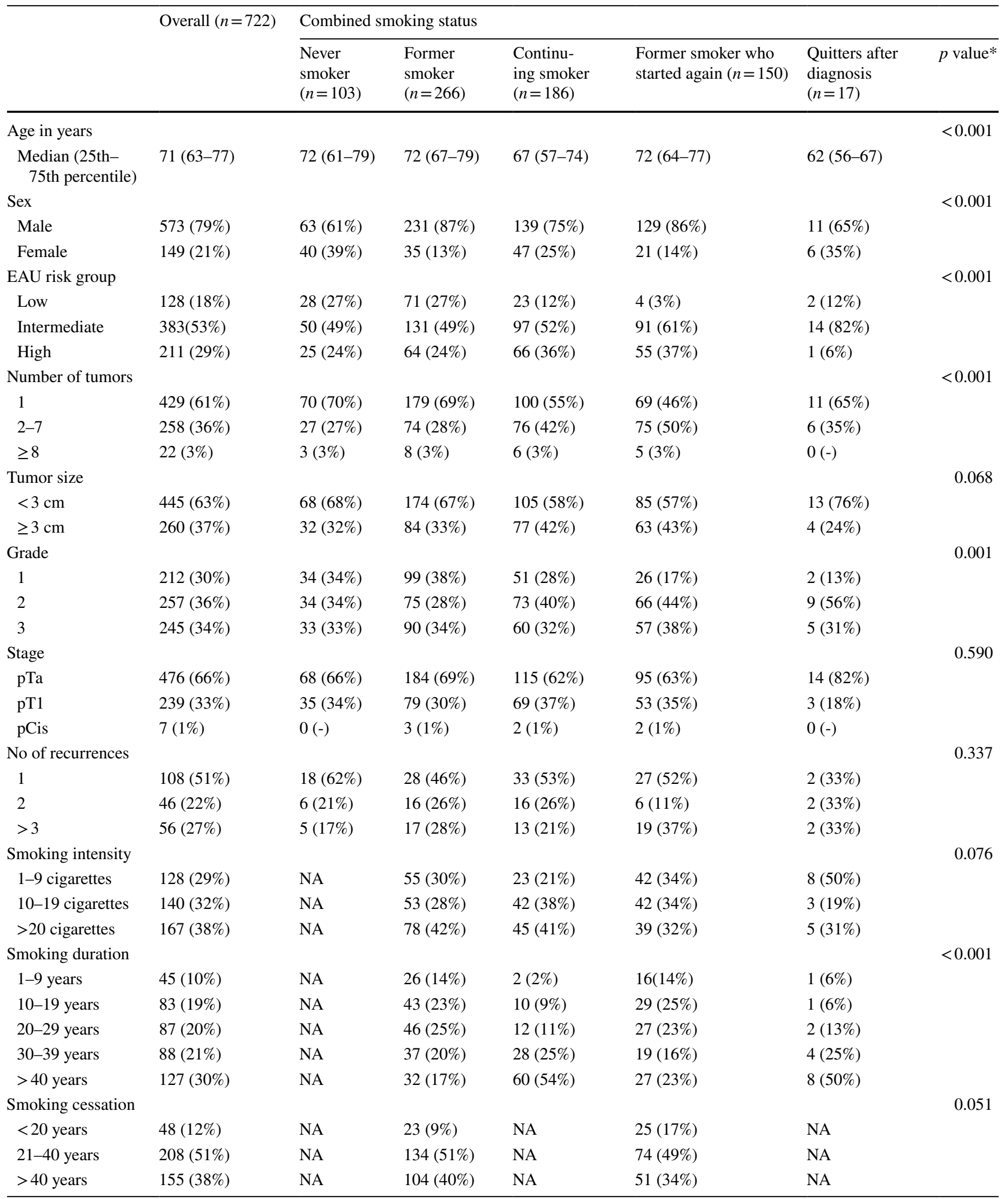

*Kruskal-Wallis test for continuous and Chi-square test for categorical variables 
Table 2 Cox regression analysis investigating the association between combined smoking status, smoking cessation before diagnosis and passive smoking, and time-to-first recurrence in NMIBC patients treated with TURBT

\begin{tabular}{|c|c|c|c|c|c|}
\hline \multicolumn{3}{|c|}{ Age and sex adjusted } & \multicolumn{3}{|c|}{ Multivariable model* } \\
\hline HR & $95 \% \mathrm{CI}$ & $\begin{array}{l}\text { Number of events/ } \\
\text { patients at risk }\end{array}$ & HR & $95 \% \mathrm{CI}$ & $\begin{array}{l}\text { Number of } \\
\text { events/patients } \\
\text { at risk }\end{array}$ \\
\hline
\end{tabular}

\begin{tabular}{|c|c|c|c|c|c|c|}
\hline \multicolumn{7}{|l|}{ Combined smoking status } \\
\hline Never smoker & 1.00 & Ref. & $29 / 103$ & 1.00 & Ref. & 28/99 \\
\hline Former smoker & 0.79 & $0.51-1.24$ & $61 / 266$ & 0.78 & $0.48-1.24$ & $59 / 254$ \\
\hline Continuing smoker & 1.17 & $0.75-1.83$ & $62 / 186$ & 1.04 & $0.65-1.66$ & $61 / 180$ \\
\hline Former smoker who started again** & 1.04 & $0.65-1.64$ & $51 / 150$ & 0.87 & $0.53-1.41$ & $49 / 146$ \\
\hline Current smoker who quit smoking $* * *$ & 1.25 & $0.52-3.00$ & $6 / 17$ & 1.47 & $0.63-3.41$ & $6 / 17$ \\
\hline \multicolumn{7}{|l|}{ Smoking cessation (in years) $* * * *$} \\
\hline$<20$ years & 0.81 & $0.46-1.43$ & $15 / 48$ & 0.82 & $0.46-1.46$ & $15 / 47$ \\
\hline $21-40$ years & 0.76 & $0.53-1.08$ & $57 / 208$ & 0.74 & $0.51-1.08$ & $54 / 200$ \\
\hline$>40$ years & 0.67 & $0.44-1.02$ & $39 / 155$ & 0.71 & $0.46-1.09$ & $38 / 148$ \\
\hline$p$ for trend & 0.070 & & & 0.126 & & \\
\hline \multicolumn{7}{|c|}{ Exposed to passive smoking during childhood? } \\
\hline No & 1.00 & Ref. & $36 / 142$ & 1.00 & Ref. & $35 / 138$ \\
\hline Yes & 1.23 & $0.86-1.75$ & $173 / 576$ & 1.17 & $0.81-1.68$ & $168 / 554$ \\
\hline \multicolumn{7}{|c|}{ Exposed to passive smoking during adulthood? } \\
\hline No & 1.00 & Ref. & $74 / 261$ & 1.00 & Ref. & $74 / 261$ \\
\hline Yes & 1.03 & $0.77-1.38$ & $135 / 454$ & 1.02 & $0.76-1.36$ & $135 / 454$ \\
\hline
\end{tabular}

*All estimates adjusted for age, sex, stage, grade, tumor size, and number of tumors

**Former smoker who started again and current smoker who quit smoking not included in former smokers at diagnosis

***Smokers who quit after their first event are considered as current smokers

$* * * *$ Reference category $=$ current smokers at diagnosis, estimates also include former smokers who started again after diagnosis

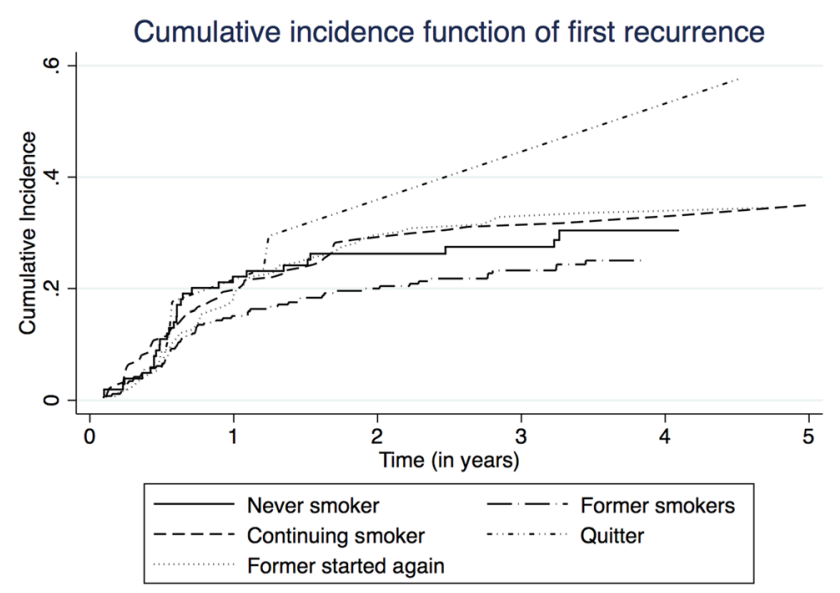

Fig. 1 Cumulative incidence functions with correction for competing risk (death) indicating cumulative incidence of first recurrence per category of smoking status in NMIBC patients treated with TURBT

For smoking duration, the HRs were divergent and did not indicate any trend $\left(p_{\text {trend }}=0.729\right)$ at all.

When considering multiple events that have occurred in patients (Table 4), the HRs are similar to the time-to-first recurrence analysis (HR for continuing vs. never smokers is $1.10,95 \% \mathrm{CI}=0.72-1.69)$. However, continuing smokers seemed to have experienced more recurrences than never smokers on average over 5 years on average, however not significantly ( 0.64 vs. $0.45, p=0.308)$.

\section{Discussion}

\section{Smoking cessation post-diagnosis and BC recurrence and clinical implications}

The reported HRs give reason to believe that quitting smoking does not influence the likelihood of NMIBC recurrence over 5 years when compared to continuing smokers in our sample. However, the number of quitters in our prospective sample was small which complicates drawing conclusions for this group. Another (retrospective) patient cohort study which assessed smoking cessation post-diagnosis concluded that quitting smoking significantly reduced risk of recurrence (HR $0.45,95 \%$ CI $0.25-0.83$, comparing quitters to continuing smokers); however, the proportion of quitters ( $43 \%$ of current smokers at diagnosis) was also 
Table 3 Multivariable Cox regression analysis concerning the association between smoking pack-years, intensity, and duration (recorded at diagnosis) with time-to-first recurrence in NMIBC patients treated with TURBT
Table 4 Conditional risk set model investigating time between multiple recurrence events in NMIBC patients treated with TURBT by smoking status at diagnosis and after diagnosis

\begin{tabular}{|c|c|c|c|c|c|c|}
\hline & \multicolumn{3}{|c|}{ Age and sex adjusted } & \multicolumn{3}{|c|}{ Multivariable model* } \\
\hline & HR & $95 \% \mathrm{CI}$ & $\begin{array}{l}\text { Number of events/ } \\
\text { patients at risk }\end{array}$ & HR & $95 \% \mathrm{CI}$ & $\begin{array}{l}\text { Number of } \\
\text { events/patients } \\
\text { at risk }\end{array}$ \\
\hline Never smoker & 1.00 & Ref. & $29 / 103$ & 1.00 & Ref. & $28 / 99$ \\
\hline \multicolumn{7}{|l|}{ Pack-years } \\
\hline 1-9 pack-years & 0.86 & $0.53-1.42$ & $36 / 141$ & 0.81 & $0.48-1.37$ & $34 / 134$ \\
\hline 10-19 pack-years & 0.95 & $0.54-1.67$ & $22 / 81$ & 0.92 & $0.51-1.65$ & $22 / 80$ \\
\hline 20-29 pack-years & 0.93 & $0.49-1.77$ & $15 / 58$ & 0.81 & $0.42-1.60$ & $15 / 57$ \\
\hline 30-39 pack-years & 0.70 & $0.35-1.43$ & $11 / 55$ & 0.60 & $0.30-1.22$ & $11 / 53$ \\
\hline$>40$ pack-years & 1.28 & $0.76-2.14$ & $30 / 86$ & 1.14 & $0.66-1.97$ & $29 / 83$ \\
\hline$p$ for trend & 0.365 & & & 0.688 & & \\
\hline \multicolumn{7}{|c|}{ Smoking intensity (cigarettes/day) } \\
\hline $1-9$ cigarettes & 0.83 & $0.50-1.38$ & $32 / 128$ & 0.81 & $0.47-1.38$ & $30 / 122$ \\
\hline 10-19 cigarettes & 0.75 & $0.45-1.28$ & $31 / 140$ & 0.61 & $0.35-1.07$ & $31 / 138$ \\
\hline $20+$ cigarettes & 1.24 & $0.79-1.96$ & $55 / 167$ & 1.16 & $0.72-1.85$ & $54 / 160$ \\
\hline$p$ for trend & 0.112 & & & 0.198 & & \\
\hline \multicolumn{7}{|c|}{ Smoking duration (in years) } \\
\hline $1-9$ years & 1.03 & $0.52-2.05$ & $12 / 45$ & 0.97 & $0.48-1.95$ & $12 / 43$ \\
\hline $10-19$ years & 0.94 & $0.54-1.62$ & $22 / 83$ & 0.85 & $0.48-1.50$ & $21 / 78$ \\
\hline $20-29$ years & 0.79 & $0.45-1.39$ & $21 / 87$ & 0.79 & $0.44-1.44$ & $20 / 85$ \\
\hline 30-39 years & 1.08 & $0.61-1.89$ & $26 / 88$ & 0.93 & $0.52-1.66$ & $25 / 85$ \\
\hline $40+$ years & 1.00 & $0.60-1.64$ & $36 / 127$ & 0.88 & $0.52-1.49$ & $36 / 124$ \\
\hline$p$ for trend & 0.917 & & & 0.729 & & \\
\hline
\end{tabular}

*All estimates adjusted for age, sex, stage, grade, tumor size, and number of tumors at diagnosis

\begin{tabular}{lllll}
\hline & HR* & $95 \%$ CI & $\begin{array}{l}\text { Number of } \\
\text { events/patients } \\
\text { at risk }\end{array}$ & $\begin{array}{l}\text { Mean number of recur- } \\
\text { rences over 5 years (95\% } \\
\text { CI) }\end{array}$ \\
\hline $\begin{array}{l}\text { Smoking status } \\
\text { Never smoker }\end{array}$ & 1.00 & Ref. & $43 / 99$ & $0.45(0.28-0.63)$ \\
Former smoker & 0.71 & $0.47-1.08$ & $108 / 254$ & $0.45(0.33-0.57)$ \\
Continuing smoker & 1.10 & $0.72-1.69$ & $116 / 180$ & $0.64(0.47-0.81)$ \\
Former smoker who started again & 0.89 & $0.56-1.43$ & $108 / 146$ & $0.82(0.57-1.06)$ \\
Current smoker who quit smoking** & 0.85 & $0.35-2.04$ & $18 / 19$ & $0.84(0.10-1.58)$ \\
\hline
\end{tabular}

*All estimates adjusted for age, sex, stage, grade, tumor size, number of tumors, and re-resection of recurrent tumor

**Smokers who have quit after their first event $(n=2)$ are also included considerably larger [14]. In another retrospective cohort study, Fleshner et al. concluded that it remained unclear whether smoking cessation at time of diagnosis is beneficial with regard to $\mathrm{BC}$ recurrence [15] although Aveyard et al. estimated that the Fleshner study shows a HR of 0.71 (95\% CI 0.48-1.05) when comparing quitters to continuing smokers [26], which is similar to the estimate observed in the study by Chen et al. Taken together, the limited evidence at this point seems to indicate that quitting smoking at or closely after diagnosis could reduce risk of recurrence. However, even across several smoking-related cancer sites such as lung cancer where this association is stronger, evidence to imply a strong, causal relationship between smoking behavior after diagnosis and recurrence is still limited [27]; so more prospective research is needed.

Considering the prolonged latency period for the development of $\mathrm{BC}$ after exposures [2], it is credible that the association between altering smoking behavior post-diagnosis and likelihood of a first recurrence or multiple recurrences over 5 years is not as strong as the association between smoking and carcinogenesis. Similarly, epidemiological evidence suggests that pre-diagnostic smoking cessation 
does not immediately lower the risk of BC [28], also indicating a longer latency period than 5 years. Furthermore, it is considered that a first $\mathrm{BC}$ recurrence is often the result of incomplete resection and/or tumor cell re-implantation, and that genuine new tumor formation only plays a more important role in later recurrences [29]. It is therefore reasonable to suggest that, because of the DNA-damaging effects of cigarette smoke [30], modifying smoking behavior may only influence later recurrences and possibly those that may occur beyond the follow-up period of 5 years reported here.

Notwithstanding the results from our study, when considering the impact of comorbidities on overall survival in $\mathrm{BC}$ patients [31] which include several smoking-related diseases [32] and other evidence indicating beneficial and significant results of post-diagnostic smoking cessation in retrospective studies [14, 15], it is evident that smoking cessation should be encouraged for NMIBC patients at diagnosis.

It is striking that only $14 \%$ of current smokers at diagnosis in our sample quit smoking post-diagnosis. There are examples of successful smoking cessation interventions in urology [33], and several studies found that when patients were diagnosed with $\mathrm{BC}$ they were more likely to quit smoking [34, 35]. Therefore, urologists should continue to improve smoking cessation counseling in newly diagnosed NMIBC patients and be updated on the available tools to improve smoking cessation figures. Moreover, more intervention clinical research investigating smoking cessation programmes in NMIBC patients is warranted.

\section{Smoking behavior pre-diagnosis and exposure to environmental tobacco smoke}

Smoking cessation was most beneficial, with regard to reducing the risk of recurrence, the longer before diagnosis it happened compared to continuing smokers. This was the strongest association observed in our study and has been observed in other studies as well, although not consistently [12]. Other results were in line with earlier studies investigating smoking status at diagnosis and $\mathrm{BC}$ recurrence as well, by indicating a slightly increased risk of recurrence in NMIBC patients for current smokers compared to never smokers in a meta-analysis [10].

Another recent study not included in the aforementioned meta-analysis shows similar HRs (HR 1.49, 95\% CI 0.95-2.33) for current smokers at diagnosis [8]. However, when including this study and our study (data from continuing smokers) in the meta-analysis, the pooled HR barely changes from 1.27 (95\% CI 1.09-1.46) to 1.26 (95\% CI 1.12-1.40) [10], indicating a significantly increased risk of recurrence for current smokers at diagnosis compared to never smokers. Possibly, the lack of association for continuing smokers in this study can be explained through multiple synchronous tumors being present at diagnosis in epithelial tumors. This theory of "field cancerization" proposes that (pre-)malignant transformation of cells has already occurred at different sites across the urothelium, explaining why (changing) smoking exposure will not have a large impact on disease prognosis [36].

Additionally, given that recent reviews indicate no considerable heterogeneity between studies that do not show an association between environmental tobacco smoke and risk of BC, it is unlikely that we would have shown any substantial association with $\mathrm{BC}$ recurrence either [37, 38].

Because no substantial association between smoking status pre-diagnosis and $\mathrm{BC}$ recurrence was observed in adjusted models it is possible that the tumor characteristics associated with BC recurrence (stage, grade, tumor size, number of tumors) included as confounders in these models overshadow the effects of smoking behavior in determining risk of BC recurrence [21] and possible also mortality since no association between quitting smoking after diagnosis and all-cause or bladder cancer-specific mortality was observed in a large retrospective cohort study [16]. Moreover, since current smokers at diagnosis in our cohort have been associated with having a higher stage, higher grade, and larger tumor size compared to never smokers [39], smoking behavior might play a more crucial role in determining risk of recurrence already before diagnosis through promoting unfavorable tumor characteristics associated with $\mathrm{BC}$ recurrence at diagnosis, although in a Dutch cohort of 323 UBC patients there was only a weak association between smoking intensity and increased risk of a more aggressive tumor type [40].

\section{Strengths and weaknesses}

Despite the prospective nature of our study there were some limitations restricting the analyses. Due to the relatively short follow-up of this study, long-term effects of smoking cessation post-diagnosis could not be assessed and the number of deaths due to $\mathrm{BC}$ in the NMIBC patients within our cohort was too low for Cox regression analysis. Also, it was not possible to obtain detailed information on adjuvant therapy for all patients, so differences in adjuvant therapy could not be considered in the statistical analysis. Additionally, we did not correct for biomarkers of BC recurrence such as mutations in the FGFR3 or TP53 genes [41], although they might work together with smoking intensity in predicting BC outcome [42].

Furthermore, one of the caveats of using only selfreported questionnaire data to assess smoking exposure was likely demonstrated in our sample of NMIBC patients. The large proportion (about 1 in 3 ) of former smokers prediagnosis who reported to have started smoking again postdiagnosis is implausible and is probably observed due to misclassification of either the questionnaire at baseline or during follow-up. A high misclassification rate (47\%) when 
comparing self-reported data on smoking behavior to cotinine values in blood was also shown in another sample of bladder cancer patients undergoing surveillance [43]. Preferably, future studies should consider more reliable ways of verifying smoking exposure through biochemical analysis.

Unfortunately, at the start of the study we did not anticipate this small proportion of quitters after diagnosis which is why the analysis concerning quitters is underpowered.

\section{Conclusion}

Although quitting smoking after diagnosis might reduce probability of recurrence based on retrospective evidence, the number of NMIBC patients quitting smoking in our prospective study was low. This indicates an important role for urologists and other health care professionals in promoting smoking cessation in NMIBC. Based on the current evidence, smoking cessation pre-diagnosis seems to have the largest impact on reducing risk of recurrence after NMIBC diagnosis.

Acknowledgments We thank all the West Midlands Consultant Urologists and their units involved with the Bladder Cancer Prognosis Programme (BCPP), as well as the BCPP research nurses. The BCPP programme was funded by Cancer Research UK and supported by the Institute of Applied Health Research (IAHR) and the Institute of Cancer of Genomic Sciences, University of Birmingham. We would also like to thank Professor Lucinda Billingham's group and Dr. Ton Ambergen from the University of Birmingham and Maastricht University, respectively, for their advice regarding the statistical analyses.

Open Access This article is distributed under the terms of the Creative Commons Attribution 4.0 International License (http://creativeco mmons.org/licenses/by/4.0/), which permits unrestricted use, distribution, and reproduction in any medium, provided you give appropriate credit to the original author(s) and the source, provide a link to the Creative Commons license, and indicate if changes were made.

\section{References}

1. Antoni S, Ferlay J, Soerjomataram I, Znaor A, Jemal A, Bray F (2017) Bladder cancer incidence and mortality: a global overview and recent trends. Eur Urol 71:96-108. https://doi.org/10.1016/j. eururo.2016.06.010

2. Bryan RT, Zeegers MP, van Roekel EH, Bird D, Grant MR, Dunn JA et al (2013) A comparison of patient and tumour characteristics in two UK bladder cancer cohorts separated by 20 years. BJU Int 112:169-175. https://doi.org/10.1111/bju.12032

3. Yan Y, Andriole GL, Humphrey PA, Kibel AS (2002) Patterns of multiple recurrences of superficial $(\mathrm{Ta} / \mathrm{T} 1)$ transitional cell carcinoma of bladder and effects of clinicopathologic and biochemical factors. Cancer 95:1239-1246. https://doi.org/10.1002/cncr.10822

4. Kaufman DS, Shipley WU, Feldman AS. Bladder cancer. Lancet 374:239-249. https://doi.org/10.1016/S0140-6736(09)60491-8
5. Roychowdhury DF, Hayden A, Liepa AM (2003) Health-related quality-of-life parameters as independent prognostic factors in advanced or metastatic bladder cancer. J Clin Oncol 21:673-678

6. Svatek RS, Hollenbeck BK, Holmäng S, Lee R, Kim SP, Stenzl A et al (2014) The economics of bladder cancer: costs and considerations of caring for this disease. Eur Urol 66:253-262. https ://doi.org/10.1016/j.eururo.2014.01.006

7. Hou L, Hong X, Dai M, Chen P, Zhao H, Wei Q et al (2016) Association of smoking status with prognosis in bladder cancer: a meta-analysis. Oncotarget Impact J. https://doi.org/10.18632/ oncotarget. 13606

8. Li HM, Azhati B, Rexiati M, Wang WG, Li XD, Liu Q et al (2016) Impact of smoking status and cumulative smoking exposure on tumor recurrence of non-muscle-invasive bladder cancer. Int Urol Nephrol. https://doi.org/10.1007/s11255-016-1441-6

9. Wilcox AN, Silverman DT, Friesen MC, Locke SJ, Russ DE, Hyun N et al (2016) Smoking status, usual adult occupation, and risk of recurrent urothelial bladder carcinoma: data from The Cancer Genome Atlas (TCGA) Project. Cancer Causes Control 27:1429-1435. https://doi.org/10.1007/s10552-016-0821-7

10. van Osch FHM, Jochems SHJ, van Schooten FJ, Bryan RT, Zeegers MP (2016) Significant role of lifetime cigarette smoking in worsening bladder cancer and upper tract urothelial carcinoma prognosis: a meta-analysis. J Urol 195:872-879. https://doi. org/10.1016/j.juro.2015.10.139

11. Gritz ER, Dresler C, Sarna L. Smoking (2005) The missing drug interaction in clinical trials: ignoring the obvious. Cancer Epidemiol Biomark Prev 14:2287-2293. https://doi.org/10.1158/10559965.EPI-05-0224

12. Simonis K, Shariat SF, Rink M (2014) Smoking and smoking cessation effects on oncological outcomes in nonmuscle invasive bladder cancer. Curr Opin Urol 24:492-499

13. Crivelli JJ, Xylinas E, Kluth LA, Rieken M, Rink M, Shariat SF (2014) Effect of smoking on outcomes of urothelial carcinoma: a systematic review of the literature. Eur Urol 65:742-754. https:// doi.org/10.1016/j.eururo.2013.06.010

14. Chen C-H, Shun C-T, Huang K-H, Huang C-Y, Tsai Y-C, Yu $\mathrm{H}-\mathrm{J}$ et al (2007) Stopping smoking might reduce tumour recurrence in nonmuscle-invasive bladder cancer. BJU Int. https://doi. org/10.1111/j.1464-410X.2007.06873.x

15. Fleshner N, Garland J, Moadel A, Herr H, Ostroff J, Trambert R et al (1998) Influence of smoking status on the disease-related outcomes of patients with tobacco-associated superficial transitional cell carcinoma of the bladder. Cancer 86:2337-2345

16. Koshiaris C, Aveyard P, Oke J, Ryan R, Szatkowski L, Stevens R et al (2017) Smoking cessation and survival in lung, upper aerodigestive tract and bladder cancer: cohort study. Br J Cancer Nat Publ Group 117:1224-1232. https://doi.org/10.1038/bjc.2017.179

17. Zeegers MP, Bryan RT, Langford C, Billingham L, Murray P, Deshmukh NS et al (2010) The west midlands bladder cancer prognosis programme: rationale and design. BJU Int 105:784788. https://doi.org/10.1111/j.1464-410X.2009.08849.x

18. Sylvester RJ, van der Meijden APM, Oosterlinck W, Witjes JA, Bouffioux C, Denis L et al (2006) Predicting recurrence and progression in individual patients with stage Ta $\mathrm{T} 1$ bladder cancer using EORTC risk tables: a combined analysis of 2596 patients from seven EORTC trials. Eur Urol 49:466-477. https://doi. org/10.1016/j.eururo.2005.12.031

19. Bryan RT, Cheng KK, James ND, Zeegers MP, Wallace DMA (2014) Re: defining progression in nonmuscle invasive bladder cancer: it is time for a new, standard definition: D. Lamm, R. Persad, M. Brausi, R. Buckley, J. A. Witjes, J. Palou, A. Böhle, A. M. Kamat, M. Colombel and M. Soloway J Urol 2014; 191 : 20-27. J Urol. https://doi.org/10.1016/j.juro.2014.01.011

20. Babjuk M, Böhle A, Burger M, Capoun O, Cohen D, Compérat EM et al (2017) EAU guidelines on non-muscle-invasive 
urothelial carcinoma of the bladder: Update 2016 [Internet]. Eur Urol. https://doi.org/10.1016/j.eururo.2016.05.041

21. Babjuk M, Oosterlinck W, Sylvester R, Kaasinen E, Böhle A, Palou-Redorta J et al (2012) EAU guidelines on non-muscleinvasive urothelial carcinoma of the bladder, the 2011 update. Actas Urológicas Españolas 36:389-402

22. Amorim LDAF, Cai J (2015) Modelling recurrent events: a tutorial for analysis in epidemiology. Int J Epidemiol 44:324-333. https://doi.org/10.1093/ije/dyu222

23. Latouche A, Allignol A, Beyersmann J, Labopin M, Fine JP (2013) A competing risks analysis should report results on all cause-specific hazards and cumulative incidence functions. J Clin Epidemiol 66:648-653. https://doi.org/10.1016/j.jclin epi.2012.09.017

24. Lammers RJM, Witjes WPJ, Hendricksen K, Caris CTM, JanzingPastors MHC, Witjes JA (2011) Smoking status is a risk factor for recurrence after transurethral resection of non-muscle-invasive bladder cancer. Eur Urol 60:713-720. https://doi.org/10.1016/j. eururo.2011.07.010

25. Hendricksen K, Aziz A, Bes P, Chun FK-H, Dobruch J, Kluth LA et al (2017) Discrepancy between European Association of urology guidelines and daily practice in the management of nonmuscle-invasive bladder cancer: results of a European survey. Eur Urol Focus. https://doi.org/10.1016/j.euf.2017.09.002

26. Aveyard P, Adab P, Cheng KK, Wallace DMA, Hey K, Murphy MFG (2002) Does smoking status influence the prognosis of bladder cancer? A systematic review. BJU Int 90:228-239. https://doi. org/10.1046/j.1464-410X.2002.02880.x

27. Warren GW, Sobus S, Gritz ER (2014) The biological and clinical effects of smoking by patients with cancer and strategies to implement evidence-based tobacco cessation support. Lancet Oncol 15:e568-e580. https://doi.org/10.1016/S1470-2045(14)70266-9

28. van Osch FH, Jochems SH, van Schooten F-J, Bryan RT, Zeegers MP (2016) Quantified relations between exposure to tobacco smoking and bladder cancer risk: a meta-analysis of 89 observational studies. Int J Epidemiol 45:857-870. https://doi. org/10.1093/ije/dyw044

29. Bryan RT, Collins SI, Daykin MC, Zeegers MP, Cheng K, Wallace DMA et al (2010) Mechanisms of recurrence of Ta/T1 bladder cancer. Ann R Coll Surg Engl 92:519-524. https://doi. org/10.1308/003588410X12664192076935

30. Corral R, Lewinger JP, Van Den Berg D, Joshi AD, Yuan J-M, Gago-Dominguez M et al (2014) Comprehensive analyses of DNA repair pathways, smoking and bladder cancer risk in Los Angeles and Shanghai. Int J Cancer 135:335-347. https://doi. org/10.1002/ijc.28693

31. Megwalu II, Vlahiotis A, Radwan M, Piccirillo JF, Kibel AS (2008) Prognostic impact of comorbidity in patients with bladder cancer. Eur Urol 53:581-589. https://doi.org/10.1016/j.eurur o.2007.10.069

32. Piccirillo JF, Tierney RM, Costas I, Grove L, Edward L. Spitznagel J, AR F et al (2004) Prognostic importance of comorbidity in a hospital-based cancer registry. JAMA 291:2441. https://doi.org/10.1001/jama.291.20.2441

33. Bjurlin MA, Cohn MR, Kim DY, Freeman VL, Lombardo L, Hurley SD et al (2013) Brief smoking cessation intervention: a prospective trial in the urology setting. J Urol 189:1843-1849. https://doi.org/10.1016/j.juro.2012.11.075

34. Bassett JC, Gore JL, Chi AC, Kwan L, McCarthy W, Chamie K et al (2012) Impact of a bladder cancer diagnosis on smoking behavior. J Clin Oncol 30:1871-1878. https://doi.org/10.1200/ JCO.2011.36.6518

35. Ostroff J, Garland J, Moadel A, Fleshner N, Hay J, Cramer L et al (2000) Cigarette smoking patterns in patients after treatment of bladder cancer. J Cancer Educ 15:86-90. https://doi. org/10.1080/08858190009528663

36. Braakhuis BJM, Tabor MP, Kummer JA, Leemans CR, Brakenhoff RH (2003) A genetic explanation of Slaughter's concept of field cancerization: evidence and clinical implications. Cancer Res 63:1727-1730

37. Osch F van, Jochems S, Wesselius A, Schooten F van, Bryan R, Zeegers M (2018) A stratified meta-analysis of the association between exposure to environmental tobacco smoke during childhood and adulthood and urothelial bladder cancer risk. Int J Environ Res Public Heal 2018 15:569. https://doi.org/10.3390/ IJERPH15040569

38. Lee PN, Thornton AJ, Hamling JS, Lee PN (2016) Epidemiological evidence on environmental tobacco smoke and cancers other than lung or breast. Regul Toxicol Pharmacol 80:134-163. https ://doi.org/10.1016/j.yrtph.2016.06.012

39. van Roekel EH, Cheng KK, James ND, Wallace DMA, Billingham LJ, Murray PG et al (2013) Smoking is associated with lower age, higher grade, higher stage, and larger size of malignant bladder tumors at diagnosis. Int J Cancer 133:446-454. https://doi. org/10.1002/ijc.28017

40. Barbosa ALA, Vermeulen SHHM., Aben KK, Grotenhuis AJ, Vrieling A, Kiemeney LA (2018) Smoking intensity and bladder cancer aggressiveness at diagnosis. PLoS ONE 13:e0194039. https://doi.org/10.1371/journal.pone.0194039

41. Bryan RT, Zeegers MP, James ND, Wallace DMA, Cheng KK (2010) Biomarkers in bladder cancer. BJU Int 105:608-613. https ://doi.org/10.1111/j.1464-410X.2009.08880.x

42. Mitra AP, Castelao JE, Hawes D, Tsao-Wei DD, Jiang X, Shi S-R et al (2013) Combination of molecular alterations and smoking intensity predicts bladder cancer outcome. Cancer 119:756-765. https://doi.org/10.1002/cncr.27763

43. Thong AE, Petruzella S, Orlow I, Zabor EC, Ehdaie B, Ostroff JS et al (2016) Accuracy of self-reported smoking exposure among bladder cancer patients undergoing surveillance at a tertiary referral center. Eur Urol Focus 2:441-444. https://doi.org/10.1016/j. euf.2015.12.002 